\title{
Molecular insights into the causes of male infertility
}

\author{
POLANi B SESHAGIRI \\ Department of Molecular Reproduction, Development and Genetics, Indian Institute of Science, \\ Bangalore 560 012, India \\ (Fax, 91-80-3600999; Email, palani@mrdg.iisc.ernet.in)
}

\begin{abstract}
Infertility is a reproductive health problem that affects many couples in the human population. About 13-18\% of couple suffers from it and approximately one-half of all cases can be traced to either partner. Regardless of whether it is primary or secondary infertility, affected couples suffer from enormous emotional and psychological trauma and it can constitute a major life crisis in the social context. Many cases of idiopathic infertility have a genetic or molecular basis. The knowledge of the molecular genetics of male infertility is developing rapidly, new "spermatogenic genes" are being discovered and molecular diagnostic approaches (DNA chips) established. This will immensely help diagnostic and therapeutic approaches to alleviate human infertility. The present review provides an overview of the causes of human infertility, particularly the molecular basis of male infertility and its implications for clinical practice.
\end{abstract}

\section{Introduction}

The recent growth of the Indian population has been unprecedented. It stands currently at over one billion and is expected to touch 2 billion by 2035 (assuming an average growth rate of $2 \%$ ). Even though curtailing population growth is a major national concern, a substantial number of infertile couples in the Indian population have an equally great concern, that of having a child. This is an equally important national problem concerning reproductive health and the infertile couples have to be treated by medically assisted reproductive technology (MART) for procreation. Globally, the incidence of infertility is estimated to be about 13-18\% (Hull et al 1985; Thonneau et al 1991; Jones and Toner 1993; Irvine 1998; Mueller and Daling 1989) in the human population, regardless of race, ethnic group, etc.

Infertility is defined as the state in which a couple wanting a child cannot conceive after 12 months of unprotected intercourse (Mueller and Daling 1989; Thonneau et al 1991). It is a problem faced by couples rather than individuals. Among the causes of infertility, about half of them could be traced to the male partner. When efforts to have children are unsuccessful, feelings of helplessness, frustration and despair are common, it can be a major life crisis for many couples. They go through enormous emotional crisis and psychological distress, as their friends and peers begin to have children. In this review article, causes of infertility in the human female and male, the molecular basis of male factor infertility and the implications of the rapidly developing molecular knowledge on infertility in the context of alleviating human infertility using MART approaches will be described.

\section{Causes of infertility}

Infertility is either primary, when no pregnancy has ever occurred, or secondary, where there has been a pregnancy, regardless of the outcome. About $67-71 \%$ and $29-33 \%$ of patients have primary and secondary infertility, respectively (Mueller and Daling 1989; Thonneau et al 1991;

Keywords. Fertility genes; infertility; medically assisted reproductive technology; Y-chromosome

Abbreviations used: AZF, Azoospermia factor; CFTR, cystic fibrosis transmembrane conductance regulator; DAZ, deleted in azoospermia; FISH, fluorescent in situ hybridization; ICSI, intra-cytoplasmic sperm injection; MART, medically assisted reproductive technology; RBM, RNA-binding motif; STD, sexually transmitted diseases. 
Irvine 1998). Female and male factors can both contribute to infertility. Idiopathic infertility is a condition of couples unable to conceive for more than two years, with no abnormalities seen on repeated investigations of tubes or as regards ovulation, luteal phase, cervical mucus, semen, sperm-oocyte interaction or intercourse. Among the major causes of infertility, chromosomal abnormalities, microdeletions, cystic fibrosis transmembrane conductance regulator (CFTR) mutations and other genetic factors [follicle stimulation hormone (FSH) receptor mutation] are important (Irvine 1998; Diemer and Desjardins 1999; Egozcue et al 2000; Hargreave 2000; Phillip et al 1998). Because immunological factors operate at almost every step in the human reproductive process, antibodies-induced damage to gametes and developing embryos is a major cause of immunological infertility. Besides, life style, environmental factors (Benoff et al 2000; Sharpe 2000), including smoking (Zenzes 2000), can affect gamete and embryo development, leading to sub(in)fertility. A combined cause of infertility is found in about 10-30\% of couples (Hill et al 1985; Jones and Toner 1993; Thonneau et al 1991). It is, therefore, important to investigate both partners and inappropriate to assume that infertility is exclusively a female or a male problem.

\section{Female infertility}

In women, the major causes of infertility, accounting for $50 \%$ of cases, are ovulation disorder and tubal damage. Other causes include endometriosis, hyperprolactinemia and reproductive tract disease (Spira 1986; Mueller and Daling 1989). Risk factors include pelvic inflammatory diseases and sexually transmitted diseases (STD). Damaged fallopian tubes are mainly responsible for infertility and Neisseria gonorrhoeae and Chlamydia trachomatis are infertility-inducing organisms. Pelvic surgery is associated with increased risk of infertility (Spira 1986; Mueller and Daling 1989). Also, ectopic pregnancy can lead to tubal infertility. A substantial number of unsafe abortions carried out in the country also contributes to infertility due to genital tract infection. It is reported that cigarette smoking can lead to tubal diseases and abnormal cervical mucous, resulting in an increased risk of infertility and childhood cancer (Zenzes 2000). In India, being a developing country, these are believed to be more prevalent, compared to developed countries.

Even though endometriosis causes infertility, the causative factors are not clearly understood. A multitude of factors are believed to be involved such as ovulatory dysfunction and alterations in gamete/embryo transport. Besides, peritoneally-derived components and macrophages are believed to affect gamete/embryo function and, immunological reactions occurring in uterine lumen affect early development. A common disorder of ovulation is polycystic ovarian syndrome, which also results in oligoovulation or anovulation and unexplained infertility (idiopathic infertility).

\section{Male infertility}

In men, the main causes of infertility are oligospermia, asthenospermia, teratozoospermia and azoospermia, which account for 20-25\% of cases (Egozcue et al 2000; Hargreave 2000). There are a number of risk factors such as STD involving $N$. gonorrhoeae and $C$. trachomatis. These cause changes in semen quality and chronic infection may lead to a block of the vas deferens or seminal vesicles (Megory et al 1987). Mumps, though rare in adults, can result in azoospermia. Anatomical abnormalities such as varicocele, vesicular damage due to torsion and obstruction of testicular sperm passage can all lead to male infertility. It is however, believed that nonobstructive azoospermia has a strong genetic basis (Hargreave 2000). Male infertility can occur either as an isolated disorder or within the framework of a known complex disorder or syndrome. There is an excess of autosomal abnormalities in men with non-obstructive azoospermia or severe oligospermia. Besides, congenital bilateral absence of the vas deferens (CBAVD) associated with the phenotype of CFTR gene mutations cause obstructive azoospermia (Donat et al 1997).

There appears to be a world-wide concern over decreasing human sperm concentration but this has been highly controversial. Decreasing sperm counts are attributed to the deleterious effects of environmental contamination by heavy metals and estrogenic chemicals (Benoff et al 2000; Mehta and Anandkumar 1997; Sharpe 2000). To what extent there is a genetic contribution is unclear. It has been reported that in a certain ethnic group, men with a particular haplotype (II) have a lower sperm concentration compared with men with haplotypes (III) and (IV) and, the frequency of haplotype (II) is more common in azoospermic men compared with normal men (Kuroki et al 1999). Based on this, it appears that the genetic contribution towards male fertility on account of a decreased sperm concentration might be significant in some ethnic groups.

\section{Molecular causes of male infertility}

Spermatogenesis is a complex process and it is subject to the influence of many genes; the molecular mechanisms involved are beginning to be understood (Diemer and Desjardins 1999; Egozcue et al 2000; Hargreave 2000). It is estimated that about 2,000 genes regulate spermato- 
genesis, most of these being present on the autosomes, with approximately 30 genes on the $\mathrm{Y}$ chromosome (Hargreave 2000). While autosomal genes that regulate spermatogenesis are concerned with regulation of metabolic process in other cells in the body as well as in spermatogenic cells, Y genes are not essential for general body function except with regard to vital male reproductive processes (Hargreave 2000). Thanks to developments in molecular genetics over the past decades, a significant proportion of idiopathic male infertility in otherwise-healthy males is now known to be genetic in origin. Despite intense efforts, only a few human "spermatogenic genes" have been identified but their precise function remains unknown.

Genetic factors involved in male infertility are manifested as chromosomal disorders, monogenic disorders, multi-factorial disorders and endocrine disorders of genetic origin (Diemer and Desjardins 1999; Egozcue et al 2000). Microdeletions of the $\mathrm{Y}$ chromosome that remove associated fertility genes have received attention of late (Chandley 1998; Vogt et al 1996). Chromosomal abnormalities are common in infertile men, for example in those who are $47 \mathrm{XXY}$ or have Klinefelter's syndrome (Egozcue et al 2000). Besides numerical abnormalities, structural abnormalities also lead to phenotypic male reproductive disorder or may predispose to severe congenital abnormality when gametes are formed (Diemer and Desjardins 1999). In one survey of infertile men $(n=9766)$, the incidence of chromosomal abnormalities was $5.8 \%$ and of these, sex chromosomal abnormalities accounted for $4.2 \%$ and autosomal abnormalities, $1.5 \%$ (Johnson 1998). The incidence of these abnormalities is quite low in normal male population (Van-Assche et al 1996). Unfortunately, such a documented data from across the Indian population is not available.

\subsection{Microdeletions in the Y-chromosome}

While microdeletions are known to occur in fertile individuals too, they are more prevalent in infertile individuals, with the deletion sizes being variable (Chandley 1998). Microdeletions have been found in the three non-overlapping regions of the $\mathrm{Y}$ chromosome characterized as azoospermia factor (AZF) a-b-c (Chandley 1998; Vogt et al 1996). Deletions in these regions can cause severe spermatogenic defects ranging from nonobstructive azoospermia to oligozoospermia. About $7 \%$ of male factor infertility has been attributed to submicroscopic deletions of the $\mathrm{Y}$ chromosome, involving deletion of two RNA-binding protein gene families viz., the RNAbinding motif-containing genes (RBM) and the deleted in azoospermia (DAZ) genes (Chai et al 1997; Ma et al 1993; Reijo et al 1996a). The most common abnormality is a microdeletion in the AZF-c region, encompassing DAZ genes (Pryor et al 1997). Defects in other $Y$ chromosome genes, autosomal genes, and X-linked genes also are known to lead to infertility.

$\mathrm{DAZ}$ and AZF-c regions are identical. In a few instances, deletions of the DAZ region (detected in leukocyte DNA) are known to be carried in sperm DNA but they do not affect fertilization, embryonic development and childbirth (Page et al 1999). In some cases, fathers are mosaic for $\mathrm{Y}$ chromosome deletion. Although leukocytes contain an intact $\mathrm{Y}$ chromosome, germ cells harbour deleted version of the $\mathrm{Y}$ chromosome. Significantly, there is a high risk of infertile men vertically transmitting microdeletions of the Y chromosome to sons born by MART approaches (Cram et al 2000).

\subsection{Y genes affecting male infertility}

Because the Y chromosome has been present for all of its evolutionary history in the mutagenic environment of spermatogenesis and it does not undergo sexual genetic recombination during meiosis, the frequency of mutations and gene defects in the "intrinsically haploid" Y-genes (single allele gene) of the $\mathrm{Y}$-chromosome, compared to $\mathrm{X}$ chromosomal and autosomal genes, is quite high. Consequently, Y-linked mutations can be expected that have adverse effects on spermatogenesis and/or normal sperm function (Hargreave 2000).

It is becoming evident that men lacking expression of fertility gene(s) of the $\mathrm{Y}$ chromosome are unable to make adequate functional sperm; the genes involved include RBM, DAZ, DFFRY, DBY and CDY (Ma et al 1993; Brown et al 1998). Most genes on the $\mathrm{Y}$ are believed to be involved in the regulation of male sexual differentiation and defects will be manifest as phenotypic abnormalities except where there are autosomal homologues of the gene, e.g. DAZ. There are several other $Y$ genes in the long arm of the $\mathrm{Y}$ but little is known about the clinical importance of these, as microdeletions in regions other than $\mathrm{AZF}-\mathrm{c}$ are infrequent. Also, the interaction between genes may be complex. For example, in the case of DFFRY and $D B Y$, complete azoospermia occurs when both genes are deleted (Brown et al 1998).

Many genes that are required for fertility have been identified in model organisms (Chubb 1993). Mutations in these genes cause infertility due to defects in development of the germ-cell lineage, but the organism is otherwise healthy. A fly homologue of DAZ, Boule, has been identified; loss of its function leads to male sterility, characterized by meiotic arrest in pachytene 1 (Eberhart et al 1996). A mouse homologue of DAZ, Dazl has also been identified (Cooke et al 1996). Its disruption leads to 
the loss of all germ cells in both sexes during prenatal germ cell development; the loss is dosage dependent, meaning that copy numbers of $D A Z$ genes decide germcell number and acquisition of morphology and mobility (Reijo et al 1996a, b; Ruggiu et al 1997). Men lacking $D A Z$ gene(s) may present with no germ cells, meiotic arrest, or simply fewer sperm (Reijo et al 1996a, b). Flies and mice, however, have autosomal DAZ homologues but no Y chromosome gene cluster. The critically important fertility genes within the $D A Z$ region, have still not been identified. It is, however, clear that infertility is caused by loss of one or more of the $D A Z$ genes; the role of other genes that map in or near the $D A Z$ gene locus in determining fertility is not yet known.

A number of germ cell-specific proteins are expressed during meiosis, such as lactate dehydrogenase $\mathrm{C} 4$, phosphoglycerate kinase 2 , cytochrome $\mathrm{c}_{\mathrm{T}}$, and the heat shock protein (HSP) 70-2 (Eddy and O'Brien 1997). Gene targeting studies in the mouse have shown that a several genes expressed during specific stages of spermatogenesis and sperm function such as primordial germ cell development and migration (TIAR, Lhx9), spermatogonial proliferation and survival (p27, Dazl), various stages of meiosis (ATM, ATR, TLS, SCP3, Msh5, Hsp70-2, cyclinA1, protamines), spermatogenesis (MHR6b, CREM, protein phosphatase $1 \mathrm{c} \gamma$, nectin-2) and fertilization (fertilin- $\beta$ ) are important for successful formation of haploid spermatids and sperm and for the fertilization process per se (Venables and Cooke 2000). In their absence, there is partial to complete arrest in meiosis, leading to male infertility with no impact on the female phenotype (Eddy and O'Brien 1997; Venables and Cooke 2000, references therein). With very few exceptions (Philip et al 1998), natural mutations involving human homologues of fertility genes have not been reported. But their important role in spermatogenesis and male fertility in humans cannot be overlooked. Also, very few fertility loci in the human $\mathrm{Y}$ chromosome have been mapped so far (Reijo et al 1996a, b; Vogt et al 1996) but they should be rapidly known since a high resolution physical map of the human Y chromosome is now available (Tilford et al 2001) not to mention the entire human genome sequence.

\subsection{RBM/DAZ genes}

There is a family of up to 50 RNA-binding motif (RBM) genes. While most copies are probably inactive, deletions of the AZF-b region causes fractional inactivation of RBM. The DAZ gene (formerly known a SPGY) is the second candidate gene involved in male fertility to be described. It is a member of a family of 6-10 genes. Both RBM and DAZ genes families encode proteins with similar structures. About 15-30 copies of RBM genes are dispersed in the short and long arms of the Y chromosome (Delbridge et al 1997) and they comprise both nonfunctional and functional copies. The RBM protein localizes to the nucleus of all spermatogenic cell types. The expression of nuclear RBM protein is restricted to male germ line in humans and mice, where as DAZ protein is cytoplasmic. RBM is highly conserved and found on the $\mathrm{Y}$ of all mammalian species examined (Delbridge et al 1997). But DAZ/SPGY is found only in humans and old world primates, but an autosomal homologue is present on chromosomes 3 and 17 in mice and humans, respectively (Cooke et al 1996). A DAZ deletion in the AZF-c region may account for abberrant spermatogenesis.

DAZ cDNA reveals that the predicted amino acid sequence contains a single RNA-binding domain and a series of repeated 24 amino acid motifs, called DAZ repeats (Reijo et al 1996a, b). The DAZ RNA-binding domain contains an RNP (RNA-binding protein) consensus sequence that is found in RNPs in diverse organisms. There are seven tandem copies of DAZ in the $Y$ chromosome, all deleted in infertile men containing DAZregion deletions (Gläser et al 1998). In addition, there is a more divergent copy of DAZ called DAZL on chromosome 3. The DAZ genes are thought to have arisen from the autosomal DAZL gene during primate evolution (Hargreave 2000). RNA substrate(s) of the proteins have not yet been identified. DAZ and DAZL proteins are present in the nucleus and cytoplasm of fetal gonocytes. In the adult testis, both proteins are abundant in the nucleus of spermatogonia but transit to the cytoplasm of primary spermatocytes at meiosis (Reijo et al 2000). Human and mouse DAZ genes function in the nucleus of premeiotic germ cells and in the cytoplasm of meiotic germ cells. The gene is required for female and male germ cell progression into meiosis (Ruggiu et al 1997). DAZL is expressed only in male and female germ cells in mice and men and is associated with spermatogenesis (Cooke et al 1996; Reijo et al 1996b). Knockout-female mice of DAZL gene show a failure of proper development of the female genital tract (Ruggiu et al 1997).

$\mathrm{RBM}$ and DAZ gene product are related to hnRNPG, a family of proteins involved in RNA metabolism including packaging of RNA, transport to the cytoplasm and splicing. RBM could be regulating splicing events essential for spermatogenesis, whereas DAZ/SPGY with its autosomal contribution is important for gametogenesis in both sexes, perhaps in the male, DAZ is important for regulating translational repression during spermatogenesis.

\section{$5.4 \quad X$ genes affecting male infertility}

Examples of X-linked genetic disorders affecting male infertility are Kaltman's syndrome (mutation in KALIG-1 
gene on Xp 22.3, involved with regulation of cell adhesion and axonal path finding) leading to hypogonadotrophic hypogonadism (Sauten and Paulsen 1973; Franco et al 1991) and Reifenstein syndrome (androgen insensitivity; defect in androgen receptor gene on Xq11-12, leading to testicular feminization with an immature female phenotype to an apparently normal but infertile male. Among other X-chromosome associated abnormalities, azoospermia with spermatogenic arrest has been shown to be due to a submicroscopic interstitial deletion on the Xp pseudoautosomal region (Gabriel-Robez et al 1990).

\section{Implications in MART}

Remarkably, MART is able to create progeny as it were from infertile couples, something that was previously thought to be impossible. Treatment of male-factor infertility has improved dramatically despite the low level or absence of sperm in the ejaculate. One of the concerns, however, is that the infertile couples, regardless of whether they can really afford treatment, out of desperation for child, are prepared to undergo even the most sophisticated MART approaches such as intra-cytoplasmic sperm injection (ICSI) using germ cells from testis [testicular sperm aspiration (TESA), round spermatid injection (ROSI) and round spermatid nucleus injection ROSNI)]. These approaches to treating male-factor infertility need to be carried out with extreme caution, in view of the possible risk of vertically transmitting defective fertility gene(s) to male progeny, i.e. when the etiology of infertility is genetic in origin (Wert 1998; Page et al 1999).

In this regard, ICSI has become a revolutionary MART treatment for male infertility and its widespread use raises medical concerns about the transfer of genetic defects to future generations. Unfortunately, there is a higher than normal frequency of sex chromosome abnormalities in children born of ICSI procedures compared with the normal population (Andrews et al 1998; Bonduelle et al 1998; Macas et al 2001). Besides, infertile men carrying Y chromosome microdeletions pass on this defect to ICSIborn sons (Cram et al 2000). During ICSI, the process of fertilization is dramatically changed. For example, there is no fertilization occurring in vivo and physiological maturation of sperm, the basis for its selection and penetration through egg investments and its influence on embryonic spatial patterning (Piotrowska and ZernickaGoetz 2001) are missing. Because ICSI bypasses early developmental mechanisms, concerns have been expressed on the possible reproductive health $\operatorname{risk}(\mathrm{s})$ for the offspring. In coming years, procedures need to be developed to evaluate an individual's sperm for genetic defects. It is worrisome that with the primary aim of providing children to the infertile couples, a variety of sophisticated MART techniques are being used to overcome male factor infertility without understanding the underlying molecular etiology. But, in the process of curing infertility to the patient, there is an high risk of transmitting abnormal paternal geno(pheno)type to a MART-born child.

In India only a small fraction of the $15-20 \%$ of married couples known to be sub- or infertile category, opt for MART. However, a substantial portion of infertile patients still remain without help for various reasons such as lack of adequate treatment options and their accessibility, high cost and fear of conceiving and bearing potentially abnormal offspring. This is despite the fact that over the years MART has become useful for couples with infertility, with a good success rate of about 20-30\% globally. There is a need for a multidisciplinary comprehensive infertility care, which should also involve structured management strategies, and this should include clinical evaluation, genetic diagnosis (PGD), genetic counseling, patient education, informed consent and most appropriate and cost effective MART approaches to infertility treatment (Liebaers et al 1998; Fasouliotis and Schenker 1999). The extremely limited health care resources available in the country makes this particularly important.

\section{Conclusion}

Our knowledge of the molecular genetics of human fertility is expanding rapidly. This has a profound impact on the way MART treatments are offered to infertile couples. It is now possible to detect the incidence of chromosomal abnormalities using a variety of highpowered polymerase chain reaction (PCR) techniques (Dana et al 1992; Kostiner et al 1998) and multicolour fluorescent in situ hybridization (FISH) analysis (Gläser and Schempp 1998; Macas et al 2001). Before patients can be subjected to ICSI, FISH-sperm studies are necessary to understand whether there is a genetic cause for male infertility. New spermatogenesis genes will be discovered (Venables and Cooke 2000) and testing mutations will become easier (DNA chips and microarray technology). These possibilities raise questions concerning the clinical impact and significance of new findings in mammalian reproduction. Diagnostic and therapeutic approaches in reproductive medicine have to keep pace with rapidly developing molecular knowledge of human reproduction; there is an urgent need to implement the increasing molecular knowledge in clinical practice. In terms of overall scientific priorities for the human race, this area of modern biology of human reproduction and 
allied science rates highly. Besides, increasing public unease about the new science of reproduction, needs to be addressed meaningfully.

\section{Acknowledgements}

Financial support from the Council of Scientific and Industrial Research and Indian Council of Medical research, New Delhi to carry out ongoing studies on mammalian sperm biology is gratefully acknowledged.

\section{References}

Andrews L, Elster N and Gatter R 1998 ART into science; regulation of fertility techniques; Science 281 651-652

Benoff S, Jacob A and Hurley I R 2000 Male infertility and environmental exposure to lead and cadmium; Hum. Reprod. 6 107-121

Bonduelle M, Aytoz A, Van Asche E, Devroey P, Liebaers I and Van Steirteghem A 1998 Incidence of chromosomal aberrations in children born after assisted reproduction through introcytoplasmic sperm injection; Hum. Reprod. 13 781-782

Brown G M, Furlong R A, Sargent C A, Erickson R P, Longepied G, Mitchell M. Jones M H, Hargreave T B, Cooke H J and Affara N A 1998 Characterization of the coding sequence and fine mapping of the human DFFRY gene and comparative expression analysis and mapping to the Sxr interval of the mouse Y chromosome of the Dffry gene; Hum. Mol. Genet. 7 97-107

Chai N N, Salido E C and Yen P H 1997 Multiple functional copies of the $R B M$ gene family, a spermatogenesis candidate of the human Y chromosome; Genomics 45 355-361

Chandley A C 1998 Chromosome anomalies and Y chromosome microdeletions as causal factors in male infertility; Hum. Reprod. 13 45-50

Chubb C 1993 Genetic control of spermatogenesis and steroidogenesis; in Cell and molecular biology of the testis (eds) C Desjardins and L L Ewing (New York: Oxford University Press) pp 90-107

Cooke H J, Lee M, Kerr S and Ruggiu M 1996 A murine homologue of the human DAZ gene is autosomal and expressed only in male and female gonads; Hum. Mol. Genet. 5 513-516

Cram D S, Ma K, Bhasin S, Arias J, Pandjaitan M, Chu B, Audrins M S, Saunders D, Quinn F, deKretser D and McLachlan R 2000 Y chromosome analysis of infertile men and their sons conceived through intracytoplasmic sperm injection: vertical transmission of deletions and rarity of de novo deletions; Fertil. Steril. 74 909-915

Dana R K, Paul J T and Renee A R 1992 Male infertility: analysis of the markers and genes on the human Y chromosome; Hum. Reprod. 13 3032-3038

Delbridge M L, Harry J L, Toder R, O’Neill R J, Ma K, Chandley A C and Graves J A 1997 A human candidate spermatogenesis gene, $R B M 1$, is conserved and amplified on the marsupial Y chromosome; Nat. Genet. 15 131-136

Diemer T and Desjardins 1999 Developmental and genetic disorders in spermatogenesis; Hum. Reprod. 5 120-140

Donat R, McNeill A S, Fitzpatrick D R and Hargreave T B 1997 The incidence of cystic fibrosis gene mutations in patients with congenital bilateral absence of the vas deferens in Scotland; Br. J. Urol. 79 74-77

Eberhart C G, Maines J Z and Wasserman S A 1996 Meiotic cell cycle requirement for a fly homologue of human deleted in Azoospermia; Nature (London) 381 783-785

Eddy E M and O'Brien D A 1997 Gene expression during mammalian meiosis; Curr. Top. Dev. Biol. 37 141-200

Egozcue S, Blanco J, Vendrell J M, Garcia F, Veiga A, Aran B, Barri P N, Vidal F and Egozcue J 2000 Human male infertility: chromosome anomalies meiotic disorders, abnormal spermatozoa and recurrent abortion; Hum. Reprod. $693-$ 105

Fasouliotis S J and Schenker J G 1999 Social aspects in assisted reproduction; Hum. Reprod. 5 26-39

Franco B, Guioli S and Pragliola A 1991 A gene deleted in Kallmann's syndrome shares homology with neural cell adhesion and axonal path-finding molecules; Nature (London) 353 529-536

Gabriel-Robez O, Rumpler Y, Ratomponirina C, Petit C, Levilliers J, Croquette M F and Couturier J 1990 Deletion of the pseudoautosomal region and lack of sex chromosome pairing at pachytene in two infertile men carrying an $\mathrm{X}-\mathrm{Y}$ translocation; Cytogen. Cell. Genet. 54 38-42

Gläser B, Yen P H and Schempp W 1998 Fibre-fluorescence in situ hybridization unravels apparently seven $D A Z$ genes or pseudogenes clustered within a Y-chromosome region frequently deleted in azoospermic males; Chromosome 6 481-486

Hargreave T B 2000 Genetic basis of male fertility; Br. Med. Bull. 56 650-671

Hull M G, Glazener C M A, Kelly N J, Conway D I, Foster P A, Hinton R A, Coulson C, Lambert P A, Watt E M and Desai K M 1985 Population study of causes, treatment, and outcome of infertility; Br. Med. J. 291 1693-1697

Irvine D S 1998 Epidemiology and etiology of male infertility; Hum. Reprod. 13 33-44

Johnson M D 1998 Genetic risks of intra-cytoplasmic sperm injection in the treatment of male infertility: recommendation for genetic counseling and screening; Fertil. Steril. 70 397411

Jones H W and Toner J P 1993 The infertile couple; N. Eng. J. Med. 329 1710-1715

Kostiner D R, Turek P J and Reijo R A 1998 Male infertility: analysis of the markers and genes on the human Y chromosome; Hum. Reprod. 13 3032-3038

Kuroki Y, Iwamoto T and Lee J 1999 Spermatogenic ability is different among males in different $\mathrm{Y}$ chromosome lineage; Hum. Genet. 44 289-292

Liebaers I, Sermon K and Staessen C 1998 Clinical experience with preimplantation genetic diagnosis and intracytoplasmic sperm injection; Hum. Reprod. 13 186-193

Ma K, Inglis J D, Sharkey A et al 1993 A Y chromosome gene family with RNA-binding protein homology: candidates for the azospermia factor AZF controlling human spermatogenesis; Cell 75 1287-1295

Macas E, Imthurn B and Keller J P 2001 Increased incidence of numerical chromosome abnormalities in spermatozoa injected into human oocytes by ICSI; Hum. Reprod. 16 115120

Megory E, Zuckerman H, Shoham Z and Lunenfeld B 1987 Infection and male fertility; Obstet. Gynecol. Survey 42283 290

Mehta R H and Anand Kumar T C 1997 Declining semen quality in Bangaloreans: a preliminary report; Curr. Sci. 72 $621-622$ 
Mueller B A and Daling J R 1989 Epidemiology of infertility. Extent of the problem-risk factors and associated social changes; in Controversies in reproductive endocrinology and infertility (ed.) M R Soules (New York: Elsevier) pp $1-13$

Page D C, Silber S and Brown L G 1999 Men with infertility caused by $A Z F C$ deletion can produce sons by intracytoplasmic sperm injection, but are likely to transmit the deletion and infertility; Hum. Reprod. 14 1722-1726

Phillip M, Arbelle J C, Segev Y and Parvari R 1998 Male hypogonadism due to a mutation in the gene for the $\beta$-subunit of follicle stimulating hormone; N. Engl. J. Med. 3381729 1732

Piotrowska K and Zernicka-Goetz M 2001 Role for sperm in spatial patterning of the early mouse embryo; Nature 409 517-521

Pryor J L, Ken-First M, Muallem A, Van Bergen A H, Nolten W E, Meisner L and Roberts K P 1997 Microdeletions in the Y chromosome of infertile men; N. Engl. J. Med. $336534-$ 539

Reijo R, Lee T Y, Salo P, Alagappan R, Brown L G, Rosenberg M, Rozen S, Jaffe T, Straus D and Hovatta O 1996a Diverse spermatogenic defects in humans caused by $\mathrm{Y}$ chromosome deletions encompassing a novel RNA-binding protein gene; Nat. Genet. 10 383-393

Reijo R, Seligman J, Dinulos M B, Jaffe T, Brown L G, Disteche C M and Page D C 1996b Mouse autosomal homolog of DAZ, a candidate male sterility gene in humans, is expressed in male sperm cells before and after puberty; Genomics 35 346-352

Reijo R A, Dorfman D M, Slee R, Renshaw A A, Loughlin K R, Cooke H and Page D C 2000 DAZ family proteins exist throughout male germ cell development and transit from nucleus to cytoplasm at meiosis in humans and mice; Biol. Reprod. 63 1490-1496

Ruggiu M, Speed R, Taggart M, McKay S J, Kilanowski F, Saunders P, Dorin J and Cooke H J 1997 The mouse Dazl gene encodes a cytoplasmic protein essential for gametogenesis; Nature (London) 389 73-77

Sauten R J and Paulsen C A 1973 Hypogonadotrophic eunuchoidism in clinical study of the mode of inheritance; $J$. Clin. Endocrinol. Metab. 36 47-54

Sharpe R M 2000 Lifestyle and environmental contribution to male infertility; Br. Med. Bull. 56 630-642

Spira A1986 Epidemiology of human reproduction; Hum. Reprod. 1 111-115

Thonneau P, Marchard S, Tallec A, Ferial M L, Ducot B, Lansac J, Lopes P, Tabaste J M and Spira A 1991 Incidence and main courses of infertility in a resident population $(1,850,000)$ of three French regions (1988-1989); Hum. Reprod. 6 811-816

Tilford, C A, Kuroda-Kawaguch, T, Skaletsky H, Rozen S, Brown L G, Rosenberg M, McPherson J D, Wylie K, Sekhon M, Kucaba TA, Waterson R H and Page D C 2001 A physical map of the human Y chromosome; Nature (London) 409 943-945

Van-Assche E, Bonduelle M, Tournaye H, Joris H, Verheyen G, Devroey P, Van Steirteghem A and Liebaers I 1996 Cytogenetics of infertile men; Hum. Reprod. 11 1-24

Venables J P and Cooke H J 2000 Lessons from knockout and transgenic mice for infertility in men; J. Endocrinol. Invest. 23 584-591

Vogt P H, Edelmann A, Kirsch S, Henegariu O, Hirschmann P, Kiesewetter F, Kohn F M, Schill W B, Farah S, Ramos C, Hartmann M, Hartschuh W, Meschede D, Behre H M, Castel A, Nieschlag E, Weidner W, Grone H J, Jung A, Engel W and Haidl G 1996 Human Y chromosome azoospermic factors (AZF) mapped to different subregions in Yq11; Hum. Mol. Genet. 5 933-943

Wert G M W R 1998 Ethics of intracytoplasmic sperm injection: proceed with care; Hum. Reprod. 13 219-227

Zenzes M T 2000 Smoking and reproduction: gene damage to human gametes and embryos; Hum. Reprod. $6123-$ 131 